\title{
Morphologic description of infectious salmon anaemia virus (ISAV)-induced lesions in rainbow trout Oncorhynchus mykiss compared to Atlantic salmon Salmo salar
}

\author{
Christine MacWilliams ${ }^{1,3}{ }^{\text {, Gerald Johnson }}{ }^{1}$, David Groman ${ }^{2}$, \\ Frederick S. B. Kibenge ${ }^{1, *}$

\begin{abstract}
${ }^{1}$ Department of Pathology and Microbiology, and ${ }^{2}$ Aquatic Diagnostic Services, Atlantic Veterinary College,
\end{abstract} \\ University of Prince Edward Island, 550 University Avenue, Charlottetown, Prince Edward Island C1A 4P3, Canada \\ ${ }^{3}$ Present address: Department of Fisheries and Oceans, Pacific Biological Station, 3190 Hammond Bay Road, Nanaimo, \\ British Columbia V9T 6N7, Canada
}

\begin{abstract}
In the present study the pathogenesis of experimental infectious salmon anaemia virus (ISAV) infection in rainbow trout Oncorhynchus mykiss (Walbaum, 1972) and Atlantic salmon Salmo salar was compared. The virus infection in the 2 species demonstrated different mortality patterns and pathology characteristics. Atlantic salmon showed a typical acute mortality pattern peaking at 8 to $16 \mathrm{~d}$ post-infection (dpi) depending on virus dose, whereas in rainbow trout, only the highest virus dose $\left(10^{7.13-7.8} \mathrm{TCID}_{50} / 200 \mu \mathrm{l}\right)$ showed a similar pattern. The middle $\left(10^{4.13} \mathrm{TCID}_{50} / 200 \mu \mathrm{l}\right)$ and lowest virus doses $\left(10^{2.13} \mathrm{TCID}_{50} / 200 \mu \mathrm{l}\right)$ in rainbow trout induced only sporadic protracted mortality, lasting up to $46 \mathrm{dpi}$. Infected rainbow trout that were live-sampled and those that died demonstrated increased erythrophagia, clusters of cellular degeneration in the haematopoietic portion of the kidney, and occasionally epicarditis, endocarditis and myocarditis. These lesions are very different from the typical necrosis in liver and kidney that occur in infected Atlantic salmon, and some of them may be indicative of an antiviral response by a resistant host to the ISAV infection. Virus was detected in the endothelium of the rainbow trout tissues using in situ hybridization, supporting our conclusions of the ISAV-induced lesions in this report.
\end{abstract}

KEY WORDS: Infectious salmon anaemia virus · ISAV · Rainbow trout pathology · Host antiviral response

Resale or republication not permitted without written consent of the publisher

\section{INTRODUCTION}

Infectious salmon anaemia (ISA) virus (ISAV), a teleost orthomyxovirus, is a commercially important viral pathogen of marine-farmed Atlantic salmon Salmo salar causing clinical disease (ISA). ISA was first described in juvenile marine-farmed Atlantic salmon in Norway in 1984 (Thorud \& Djupvik 1988) Since then, the disease has been reported in marine-farmed Atlantic salmon in Scotland (Rodger et al. 1998), New Brunswick (Bryne et al. 1998) and Nova Scotia, Canada (Ritchie et al. 2001), Faeroes Island (Anonymous 2000), Maine, USA (Bouchard et al. 2001), and most recently in Chile (OIE Report (2007)). It is unknown if disease occurs in infected wild free-ranging Atlantic salmon, as these fish are considered to be more resistant than the marine-farmed Atlantic salmon due either to genetic variation or to stress caused by management practices on the salmon farm (Nylund et al. 2003).

The disease is characterized by severe anaemia and highly variable cumulative mortalities ranging from none, to surpassing $50 \%$ of the affected population in marine-farmed Atlantic salmon. Numerous associated gross lesions have been reported including ascites, exophthalmia, petechiation of the visceral adipose tissue, and enlargement and congestion of the liver and 
spleen. Microscopic lesions include haemorrhagic liver necrosis (Thorud \& Djupvik 1988, Evensen et al. 1991, Gattuso et al. 2002), renal haemorrhage and tubular necrosis (Simko et al. 2000), filamental sinus congestion of the gill (Jones \& MacKinnon 1999), splenic congestion with concomitant erythrophagocytosis, and congestion of the lamina propria of the stomach and foregut (Evensen et al. 1991).

ISAV has also been isolated from diseased coho salmon Oncorhynchus kisutch in Chile (Kibenge et al. 2001) and from apparently healthy seawater-reared rainbow trout O. mykiss in Ireland (Siggins 2002). The virus may infect and replicate in sea trout Salmo trutta L., brown trout $S$. trutta, rainbow trout $O$. mykiss, eels Anguilla rostrata, herring Clupea harengus, and Arctic char Salvelinus alpinus resulting in asymptomatic, potentially life-long, carriers of the virus (Nylund et al. 1994, 1995b, 1997, Nylund 2003; Nylund \& Jakobsen 1995, Rolland \& Nylund, 1998, Devold et al. 2000, Snow et al. 2001). The Pacific salmonid species, chum $O$. keta, steelhead $O$. mykiss, chinook O. tshawytscha, and coho $O$. kisutch were also found to be resistant to experimental infection with ISAV even with doses as high as $10^{8} \mathrm{TCID}_{50} \mathrm{ml}^{-1}$ that induced $98 \%$ mortality in Atlantic salmon (Rolland \& Winton 2003). Although attempts to isolate the virus from some of these fishes have not been successful, the virus can be detected by RT-PCR (Devold et al. 2000, Raynard et al. 2001, Snow et al. 2001, Nylund et al. 2003). Such covert infections in the wild fishery are considered to be a source of strains that cause clinical disease in marine-farmed Atlantic salmon (Murray et al. 2002, Nylund et al. 2003). Conversely, the sea cages with farmed Atlantic salmon may represent a source of transmission of ISAV to native, wild salmonid stocks. We recently observed that the most virulent ISAV strains also cause mortality in rainbow trout with lesions characteristic of ISA (Kibenge 2004, Kibenge et al. 2006). In the present paper we describe further investigations of the pathology associated with experimental ISAV infection in rainbow trout. We show that, in contrast to the experimental disease in Atlantic salmon which is indicative of an acute infection, in rainbow trout evidence supports a more protracted infection. The lesions in rainbow trout are very different from the typical necrosis in liver and kidney that occur in infected Atlantic salmon, and some of them, such as erythrophagia, may be indicative of an antiviral response by a resistant host to the ISAV infection.

\section{MATERIALS AND METHODS}

Virus and cell cultures. The ISAV isolate NBISA01 (Jones \& MacKinnon 1999) was propagated in CHSE214 and TO cell lines as previously described (Kibenge et al. 2000, 2001). Serial 10 -fold dilutions of viral stocks were inoculated on $24 \mathrm{~h}$ old cell monolayers in 48-well plates. The virus titre (expressed as $\mathrm{TCID}_{50} / 100 \mu \mathrm{l}$ ) in each cell line was calculated using the method described by Reed \& Muench (1938).

Fish and rearing conditions. A total of 600 Atlantic salmon parr, St. John River stock (mean weight $16 \mathrm{~g}$ ) were obtained from the Cardigan Fish Hatchery, Prince Edward Island, Canada, and 600 rainbow trout, Kamloops strain (mean weight $11 \mathrm{~g}$ ) certified as specific pathogen-free were obtained from Trout Lodge via the Dover Fish Hatchery, Prince Edward Island, Canada. The fish were maintained in the Aquatic Animal Facility of the Atlantic Veterinary College in $1 \mathrm{~m}$ diameter fibreglass-reinforced plastic tanks using a freshwater flow-through system at a temperature of approximately $11^{\circ} \mathrm{C}$. Rainbow trout were adipose finclipped on arrival for identification purposes. The fish were acclimatized for $7 \mathrm{~d}$ before use.

Experimental infection of fish with ISAV and fish sampling. The experimental procedures were performed in accordance with the guidelines of the Canadian Council of Animal Care (Olfert et al. 1993). The fish were removed from stock-holding tanks and anaesthetized by immersion in an aerated solution of tricaine methane sulphonate (TMS-222) (100 $\mathrm{mg} \mathrm{l}^{-1}$ ) and a combination of 80 rainbow trout and 80 Atlantic salmon were serially assigned to each of 6 experimental groups and infected by intraperitoneal injection of one of 6 different ISAV dose/cell line combinations: TO cell linepropagated virus $10^{4.13}, 10^{6.47}$, or $10^{7.8} \mathrm{TCID}_{50} / 200 \mu \mathrm{TO}$ cell lysate per fish, and CHSE-214 cell line-propagated virus $10^{2.13}, 10^{4.13}$, or $10^{7.13} \mathrm{TCID}_{50} / 200 \mu \mathrm{l}$ CHSE-214 cell lysate per fish, and returned to their individual tanks. Eighty rainbow trout and 80 Atlantic salmon were left uninfected in the control tank in a separate 'clean room' for use as negative system control. All fish were observed twice daily and mortalities were recorded and removed for the $8 \mathrm{wk}$ duration of the trial. During the 3 wk period coinciding with the majority of mortalities, fresh mortalities (collected within $1.5 \mathrm{~h}$ of death or less) or severely moribund fish (euthanized by blunt cranial trauma) were removed from the tanks for postmortem examination and tissue sampling. Fish were considered to be moribund if they were swimming slowly at the surface separate from the general population and were unresponsive, allowing easy netting. Other clinical signs observed included difficulty maintaining an upright body position and spiral swimming patterns. Of the 341 Atlantic salmon that died during the trial, 92 were collected within $1 \mathrm{~h}$ of death or while moribund. Of the 104 rainbow trout that died during the trial, 27 were collected promptly. In all cases gross lesions were recorded by one of 2 examiners, and tissues (head kidney, liver, heart and pyloric caeca) were individually 
sampled. Samples for virus analysis were not collected from these fish, as gross and microscopic lesions were expected to be sufficient to diagnose ISA. The tissues collected were fixed in $10 \%$ neutral-buffered formalin for histologic examination.

Subject to the availability of fish, each week, 5 fish from each species from each tank were randomly sampled, anaesthetized by immersion in an aerated solution of tricaine methane sulphonate (TMS-222) $\left(100 \mathrm{mg} \mathrm{l}^{-1}\right)$, then sacrificed. In this case all tissues were bisected aseptically. Half of each tissue was fixed in $10 \%$ neutral-buffered formalin, and the other half was pooled by species (excluding the pyloric caeca) and placed in a sterile bag and stored at $-80^{\circ} \mathrm{C}$ until used for viral analysis by RT-PCR. All formalin-fixed tissues were processed in an automatic tissue processor and embedded in paraffin wax. Serial 5 to $6 \mu \mathrm{m}$ thick sections of the tissues were stained with haematoxylin and eosin (H\&E) for light microscopy.

Haematocrit analysis. During the weekly sampling, blood samples were collected into heparinized microhaematocrit capillaries from control and infected rainbow trout. Haematocrit values were determined within 30 min of sampling using a microhaematocrit centrifuge $(8000 \times g$ for $5 \mathrm{~min})$.

RT-PCR. Viral RNA was extracted from $300 \mu \mathrm{l}$ volumes of pooled tissue homogenates using TRIZOL reagent (Invitrogen Life Sciences) following the manufacturer's protocol. The ISAV F5/R5 primer set and conditions used to detect ISAV by RT-PCR were as previously described (Kibenge et al. 2000).

Statistical analysis. Survival analysis is a statistical procedure that allows quantitative prediction of the time until an event (or failure) occurs. In this study, the outcome variable of interest was the death of the fish. The mean time to failure (MTTF) denotes the time at which there is a $50 \%$ probability of death of the study population. The MTTF for each species, in each cell line, for each viral dose was estimated by Kaplan-Meier survival curves (Dohoo et al. 2003). Between-group comparisons were done using a nonparametric log-rank test. All analyses were done using the Kaplan-Meier survival model of MINITAB version 13 statistical software.

In situ hybridization (ISH). A subsequent rainbow trout challenge trial was conducted in order to demonstrate the cellular distribution of ISAV gene expression in experimentally infected rainbow trout tissues. ISH was performed on the fish tissues using the ISAV RNA segment 7 riboprobe following the procedure detailed by Moneke et al. (2003). Briefly, the serial tissue sections were rehydrated in decreasing concentrations of ethanol to a final wash in diethyl pyrocarbonate (DEPC)-treated water. The cells were permeabilized and then hybridized with approximately $25 \mathrm{ng}$ of the riboprobe in hybridization buffer per slide. ISH signals were developed using the Dig-UTP-Detection kit (Roche Diagnostics); they were then observed using light microscopy and the images captured digitally were enhanced and analyzed using Adobe Photoshop as previously described (Moneke et al. 2003).

\section{RESULTS}

\section{Mortality patterns}

No signs of illness were observed in the fish prior to the virus challenge. The total mortality for each species within each virus dose is shown in Fig. 1. The mortality level increased with increasing virus dose except for the Atlantic salmon mortalities in the groups inoculated with CHSE-214-propagated virus, where the lowest virus dose group experienced higher mortality than the middle virus dose group. Each virus dose induced considerably higher mortality in Atlantic salmon than in rainbow trout.

A fungal infection was seen in the Atlantic salmon population during the trial and formalin bath treatments were administered as indicated. Unknown to the researchers, these fish had been exposed to surface water prior to delivery. No gross fungal lesions occurred on any of the rainbow trout during the experiment; however, mild to moderate fin erosion began to develop in this population during the later stages of the trial, being observed on 14 of the 90 rainbow trout sampled in the final $3 \mathrm{wk}$. To better evaluate the effect of these secondary disease conditions, the statistical analysis of the mortality data was run twice, using the original dataset and using a second dataset modified to exclude any fungus-positive fish that had no gross lesions suggestive of an ISAV infection. As no changes in significance between the 2 datasets were found, only the results from the original, unmodified data will be discussed in this paper.

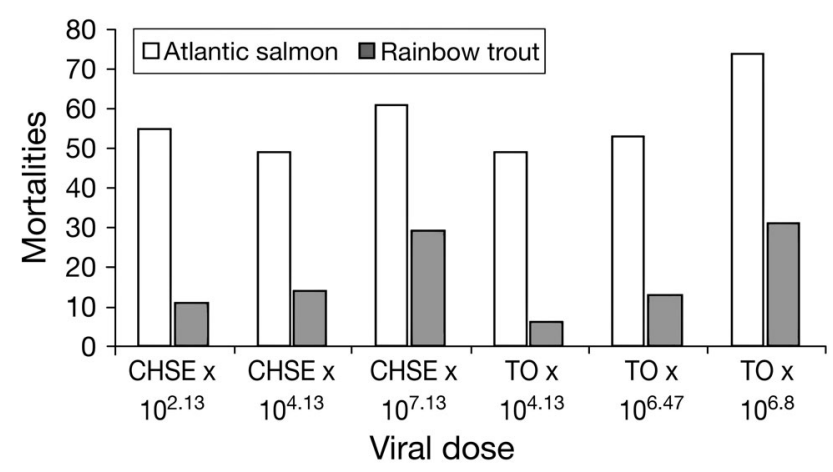

Fig. 1. Salmo salar and Oncorhynchus mykiss. Total mortalities of Atlantic salmon and rainbow trout challenged with 3 virus doses of infectious salmon anaemia virus (ISAV) grown in 2 cell lines, CHSE-214 and TO 
In general, the experimental disease in Atlantic salmon was indicative of an acute infection whereas in rainbow trout, both acute and protracted diseases were observed depending on the infective dose. The cumulative daily mortality for the highest virus dose of the CHSE-214-propagated virus is depicted in Fig. 2. Atlantic salmon showed a typical acute mortality pattern with the majority of mortalities occurring between 8 and $16 \mathrm{~d}$ post-infection (dpi) and with the final mortality on Day 21 pi. Of the 80 Atlantic salmon in this tank, 64 died and 16 were available for routine sampling. This can be compared with the rainbow trout mortalities, wherein 29 of the original population of 80 died during the trial, with the majority of deaths occurring between Days 6 and 14 pi and the final death occurring on Day 27 pi. This can be contrasted with the results observed in the tank infected with low dose CHSE-214propagated virus. At the lower infective dose, 55 of the 82 Atlantic salmon died during the trial. The majority of deaths occurred between 12 and 22 dpi with the final death on Day 28 pi. For the rainbow trout given the lower infective dose, only 11 of 80 fish died during the trial. No mortality pattern for rainbow trout was discernable, with deaths occurring sporadically between 10 and 46 dpi. Similar patterns and numbers were generated in the tanks infected with TO-propagated virus.

In order to compare the cumulative mortalities between treatments and species, a survival analysis using MTTF was done. This method allows a comparison of the treatments that accounts for the presence of data censoring or rather the random removal of 5 living fish from each tank at weekly intervals. For example, for the tank with the highest virus dose of the CHSE-214propagated virus (Fig. 2), 5 rainbow trout were removed weekly for 7 consecutive weeks, totaling 35 fish that did not die, but might have. Alternatively, only 16 Atlantic salmon from the same tank were available for routine sampling, as the original population of 80 was exhausted due to high mortalities by $28 \mathrm{dpi}$.

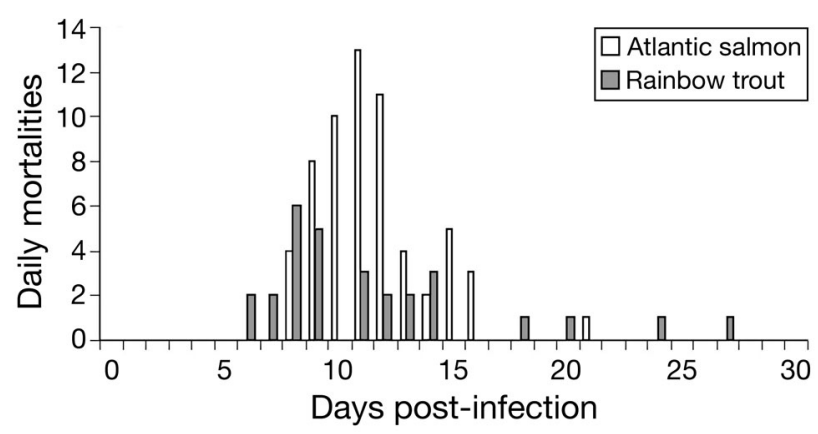

Fig. 2. Salmo salar and Oncorhynchus mykiss. Mortality plot of Atlantic salmon and rainbow trout infected with the virus dose of $10^{7.13} \mathrm{TCID}_{50} / 200 \mu \mathrm{l}$ per fish of CHSE-214-grown infectious salmon anaemia virus (ISAV)
Three comparisons are possible on data involving 2 species, 2 cell lines and 3 virus doses. Survival analysis was run for each species comparing each dose level of virus propagated in the 2 different cell lines. Tables 1 to 4 summarize the results of these analyses. The survival analysis for rainbow trout in the tanks inoculated

Table 1. Oncorhynchus mykiss. Mean time to failure (MTTF) for rainbow trout infected with 3 different doses of infectious salmon anaemia virus (ISAV) propagated in the CHSE-214 cell line. Significant differences between tanks denoted with superscript letters

\begin{tabular}{|lcccc|}
\hline Virus dose in tank & MTTF & SEM & $\begin{array}{c}\text { Lower } \\
95 \% \text { CI }\end{array}$ & $\begin{array}{c}\text { Upper } \\
\text { 95 CI }\end{array}$ \\
\hline CHSE-214 $\times 10^{7.13}$ & $21.0169^{\mathrm{a}}$ & 0.9550 & 19.1453 & 22.8886 \\
CHSE-214 $\times 10^{4.13}$ & $34.1476^{\mathrm{b}}$ & 1.1142 & 31.9638 & 36.3314 \\
CHSE-214 $\times 10^{2.13}$ & $42.3494^{\mathrm{c}}$ & 1.1554 & 40.0849 & 44.6139 \\
\hline
\end{tabular}

Table 2. Salmo salar. Mean time to failure (MTTF) for Atlantic salmon infected with 3 different doses of infectious salmon anaemia virus (ISAV) propagated in the CHSE-214 cell line. Significant differences between tanks denoted with superscript letters

\begin{tabular}{|lcccc|}
\hline Virus dose in tank & MTTF & SEM & $\begin{array}{c}\text { Lower } \\
95 \% \text { CI }\end{array}$ & $\begin{array}{c}\text { Upper } \\
95 \% \text { CI }\end{array}$ \\
\hline CHSE-214 $\times 10^{7.13}$ & $12.8918^{\mathrm{a}}$ & 0.4678 & 11.9749 & 13.8087 \\
CHSE-214 $\times 10^{4.13}$ & $18.2658^{\mathrm{b}}$ & 0.6895 & 16.9145 & 19.6171 \\
CHSE-214 $\times 10^{2.13}$ & $19.7263^{\mathrm{b}}$ & 0.6109 & 18.5290 & 20.9237 \\
\hline
\end{tabular}

Table 3. Oncorhynchus mykiss. Mean time to failure (MTTF) for rainbow trout infected with 3 different doses of infectious salmon anaemia virus (ISAV) propagated in the TO cell line. Significant differences between tanks denoted with superscript letters

\begin{tabular}{|lcccc|}
\hline Virus dose in tank & MTTF & SEM & $\begin{array}{c}\text { Lower } \\
95 \% \text { CI }\end{array}$ & $\begin{array}{c}\text { Upper } \\
95 \% \text { CI }\end{array}$ \\
\hline TO $\times 10^{7.8}$ & & & & \\
TO $\times 10^{6.47}$ & $18.4506^{\mathrm{a}}$ & 0.9649 & 16.5594 & 20.3419 \\
TO $\times 10^{4.13}$ & $32.5817^{\mathrm{b}}$ & 0.9736 & 30.6735 & 34.4899 \\
& $30.0899^{\mathrm{b}}$ & 0.4610 & 29.1864 & 30.9933 \\
\hline
\end{tabular}

Table 4. Salmo salar. Mean time to failure (MTTF) for Atlantic salmon infected with 3 different doses of infectious salmon anaemia virus (ISAV) propagated in the TO cell line. Significant differences between tanks denoted with superscript letters

\begin{tabular}{|lcccc|}
\hline Virus dose in tank & MTTF & SEM & $\begin{array}{c}\text { Lower } \\
95 \% \text { CI }\end{array}$ & $\begin{array}{c}\text { Upper } \\
95 \text { CI }\end{array}$ \\
\hline TO $\times 10^{7.8}$ & & & & \\
TO $\times 10^{6.47}$ & $9.9481^{\mathrm{a}}$ & 0.2487 & 9.4607 & 10.4356 \\
TO $\times 10^{4.13}$ & $15.0873^{\mathrm{b}}$ & 0.3897 & 14.3236 & 15.8511 \\
& $19.5962^{\mathrm{c}}$ & 0.5885 & 18.4429 & 20.7496 \\
\hline
\end{tabular}


with each of the 3 CHSE-214-propagated virus doses is presented in Table 1. The Kaplan-Meier Survival Plot corresponding to Table 1 is depicted in Fig. 3 as being representative of the data in this study. Logrank comparison demonstrated a significant difference between the survival curves of the highest virus dose $\left(10^{7.13}\right.$ TCID $\left._{50}\right)$ tank versus the middle virus dose $\left(10^{4.13} \mathrm{TCID}_{50}\right)$ tank $(\mathrm{p}=0.0028)$, versus the lowest virus dose $\left(10^{2.13} \mathrm{TCID}_{50}\right)$ tank $(\mathrm{p}=0.0002)$. Similar results were seen for the MTTFs of the Atlantic salmon infected with 3 doses of ISAV propagated in the TO cell line (Table 3). However, for rainbow trout infected with 3 doses of ISAV propagated in the TO cell line and for Atlantic salmon infected with ISAV propagated in the CHSE-214 cell line, there were significant differences found between the high dose MTTF and other levels, but the differences found between the MTTFs of the low and mid doses were not significantly different and could be attributed to chance alone.

A second set of comparisons was run between the species within each tank at each infectious dose. Atlantic salmon had a significantly shorter MTTF when compared to rainbow trout $(\mathrm{p}=0.0000)$ at all treatment levels for both sources of inoculum (virus propagated in TO or CHSE-214 cell line).

Finally, comparison of the MTTFs of the 2 different virus preparations at $10^{4.13} \mathrm{TCID}_{50}$ did not indicate a significant cell line associated change in virulence for either species of fish. The MTTF for rainbow trout in the TO-propagated virus was 30.09 as compared with the MTTF of 34.15 for rainbow trout inoculated with the CHSE-214-propagated virus ( $p=0.071)$. For Atlantic salmon, the difference between the MTTFs, 19.6 and 18.27 respectively, was even less $(p=0.205)$.

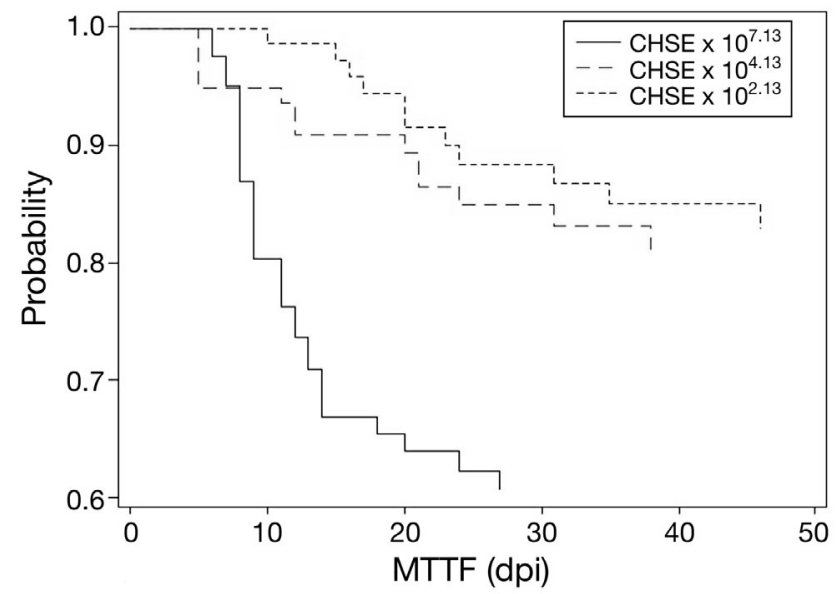

Fig. 3. Oncorhynchus mykiss. Non-parametric Kaplan-Meier survival plot for mean time to failure (MTTF) of the fish for rainbow trout inoculated with 3 doses of infectious salmon anaemia virus (ISAV) grown in CHSE-214 cell line. dpi: days post-infection. Solid line: high-dose tank; large dashed line: middose tank; small dashed line: low-dose tank

\section{Haematocrit values}

Two-way ANOVA determined significant differences at the tank level $(F=14.42 ; \mathrm{df}=6 ; \mathrm{p}=0.000)$ and Bonferroni pairwise comparisons found that the control tank mean haematocrit value was significantly higher than those of each of the infected tanks. In the rainbow trout control group, the mean haematocrit was 44.78 , range 28 to $60(\mathrm{n}=37)$. The lowest mean haematocrit (Hct $=32.64$, range 20 to $42, \mathrm{n}=36$ ) was found in the fish inoculated with high dose TO-propagated ISAV. No significant difference was noted in haematocrit values taken over the 8 sampling periods, or in the interactions between infected tanks and date of sampling.

\section{Viral detection using RT-PCR}

Table 5 summarizes the results of virus detection by RT-PCR in pooled tissue samples of fish from the weekly live sampling. No obvious cell line-associated or dose-related patterns were discernable from this data. On Day 7 pi, positive RT-PCR results were obtained for Atlantic salmon in the low virus dose tanks of both cell lines and for rainbow trout infected with the low dose CHSE-214-propagated virus. Day 14 pi had the highest number of RT-PCR positive samples, with 3 of the 6 rainbow trout tissue pools and 2 of the 6 Atlantic salmon tissue pools being positive.

\section{Gross pathology of recent mortalities or moribund fish}

The descriptions of the terminal lesions of Atlantic salmon in this study are based on a subset of 12 recent mortalities or moribund fish that were collected for purposes of confirming pathogenicity of the virus and the compatibility of lesions with those characteristic of ISA (Mullins et al. 1998, O'Halloran et al. 1999). These fish were collected during the period when the majority of mortalities were occurring in the high-dose tanks, between 9 and 13 dpi, and included fish inoculated with ISAV propagated in both TO and CHSE-214 cell lines. In contrast, all the recent mortalities and moribund rainbow trout collected were examined (total of 27). The rainbow trout died between 6 and 36 dpi, with 9 of the 27 fish dying after the initial $3 \mathrm{wk}$ of the trial, when the majority of mortalities had already occurred. The gross pathology lesions are summarized in Table 6. The most common lesions in Atlantic salmon were liver congestion, visceral adipose petechiation, ascites, periorbital petechiation, splenic 
Table 5. Oncorhynchus mykiss and Salmo salar. Summary of RT-PCR results for detection (+/-) of infectious salmon anaemia virus (ISAV) in pooled samples of 5 fish per tank (CSHE-214- or TO-propagated virus doses) at each sampling interval. dpi: days post-infection; RT: rainbow trout; AS: Atlantic salmon; ND: not done

\begin{tabular}{|c|c|c|c|c|c|c|c|c|c|c|c|c|}
\hline \multirow[t]{2}{*}{ dpi } & \multicolumn{2}{|c|}{ CHSE- $214 \times 10^{2.13}$} & \multicolumn{2}{|c|}{ CHSE- $214 \times 10^{4.13}$} & \multicolumn{2}{|c|}{ CHSE- $214 \times 10^{7.13}$} & \multicolumn{2}{|c|}{$\mathrm{TO} \times 10^{4.13}$} & \multicolumn{2}{|c|}{$\mathrm{TO} \times 10^{6.47}$} & \multicolumn{2}{|c|}{$\mathrm{TO} \times 10^{7.8}$} \\
\hline & RT & AS & $\mathrm{RT}$ & AS & $\mathrm{RT}$ & AS & RT & AS & RT & AS & RT & AS \\
\hline 7 & + & + & - & - & - & - & - & + & - & - & - & - \\
\hline 14 & + & - & - & - & + & + & + & - & - & - & - & + \\
\hline 21 & - & - & - & - & - & + & - & - & - & - & - & ND \\
\hline 28 & - & - & - & - & - & - & + & - & - & - & - & ND \\
\hline 35 & - & - & + & + & - & ND & - & - & + & ND & - & ND \\
\hline 42 & - & ND & - & - & - & ND & - & - & - & ND & - & ND \\
\hline 49 & - & ND & - & ND & + & - & - & ND & - & ND & - & ND \\
\hline 56 & - & ND & - & ND & - & ND & - & ND & - & ND & - & ND \\
\hline
\end{tabular}

congestion, and pale gills. These experimentally induced ISA lesions mimic gross lesions that have been observed in Atlantic salmon retrieved from ISAVinfected cage sites in the Bay of Fundy (Mullins et al. 1998, O'Halloran et al. 1999). Of these, only visceral adipose petechiation and ascites were commonly observed lesions among the rainbow trout mortalities. Conversely, the infrequent Atlantic salmon gross lesions of fin base haemorrhage and exophthalmos were common in the rainbow trout mortalities.

\section{Histopathology of recent mortalities or moribund fish}

Liver, anterior kidney, heart and pyloric caeca were examined by histopathology. The histopathologic lesions are summarized in Table 7. In contrast to Atlantic salmon, the rainbow trout rarely (2 of 27 ) had liver necrosis. Fig. 4 shows the most common microscopic lesion in the rainbow trout, which consisted of uni- to multi-cellular degeneration of an unknown cell type in the haematopoietic portion of the kidney. In contrast to Atlantic salmon, which had no epicarditis/ endocarditis, 5 of 27 rainbow trout had cardiac lesions ranging from mild epicarditis/endocarditis to severe endocarditis with adjacent degeneration of the compact myocardium of the ventricle. Fig. 5 shows this myocardial involvement, which we believe represents a unique lesion associated with ISAV infection in rainbow trout. The first cardiac lesion was evident in a fatally infected rainbow trout $6 \mathrm{dpi}$, but the most severe cardiac lesion was found in a mortality on Day 35 pi. However, from the microscopic evaluation of these myocardial lesions, the pathogenesis of lesion development could not be determined.

Table 6. Salmo salar and Oncorhynchus mykiss. Prevalence (Prev.) of gross lesions in recent mortalities or moribund fish experimentally infected with infectious salmon anaemia virus (ISAV)

\begin{tabular}{|lrrrr|}
\hline \multirow{2}{*}{ Gross pathologic lesion } & \multicolumn{3}{c}{$\begin{array}{c}\text { Atlantic salmon } \\
(\mathrm{n}=12)\end{array}$} & \multicolumn{2}{c|}{$\begin{array}{c}\text { Rainbow } \\
(\mathrm{n}=27) \\
\end{array}$} & Prev. & $\%$ & \multicolumn{2}{c}{ Prev. } & $\%$ \\
\hline Liver congestion & 12 & 100.0 & 6 & 22.2 \\
Visceral adipose petechiation & 11 & 91.7 & 12 & 44.4 \\
Ascites & 10 & 83.3 & 11 & 40.7 \\
Periorbital petechiation & 8 & 66.7 & 3 & 11.1 \\
Splenic congestion & 7 & 58.3 & 4 & 14.8 \\
Pale gills & 6 & 50.0 & 0 & 0.0 \\
Exophthalmos & 4 & 33.3 & 12 & 44.4 \\
Fin base haemorrhage & 1 & 8.3 & 14 & 51.9 \\
Cardiac congestion & 1 & 8.3 & 0 & 0.0 \\
Pyloric caeca congestion & 1 & 8.3 & 3 & 11.1 \\
\hline
\end{tabular}

Table 7. Salmo salar and Oncorhynchus mykiss. Prevalence (Prev.) of histopathologic lesions in recent mortalities or moribund fish experimentally infected with ISAV

\begin{tabular}{|lrrrr|}
\hline Histopathologic lesion & \multicolumn{2}{c}{$\begin{array}{c}\text { Atlantic salmon } \\
(\mathrm{n}=12)\end{array}$} & \multicolumn{2}{c|}{$\begin{array}{c}\text { Rainbow trout } \\
(\mathrm{n}=27)\end{array}$} \\
& Prev. & $\%$ & Prev. & $\%$ \\
\hline Liver congestion and haemorrhage & 10 & 83.3 & 11 & 40.7 \\
Liver necrosis & 8 & 66.7 & 2 & 7.4 \\
Renal haematopoietic cell degeneration & 8 & 66.7 & 25 & 92.6 \\
Increased erythrophagocytosis & 8 & 66.7 & 22 & 77.8 \\
Pyloric caeca congestion and haemorrhage & 7 & 58.3 & 4 & 14.8 \\
Renal congestion and haemorrhage & 2 & 16.7 & 4 & 14.8 \\
Cardiac endothelial cell hypertrophy & 2 & 16.7 & 4 & 14.8 \\
Epicarditis/endocarditis & 0 & 0.0 & 5 & 18.5 \\
Renal necrosis & 0 & 0.0 & 1 & 3.7 \\
\hline
\end{tabular}




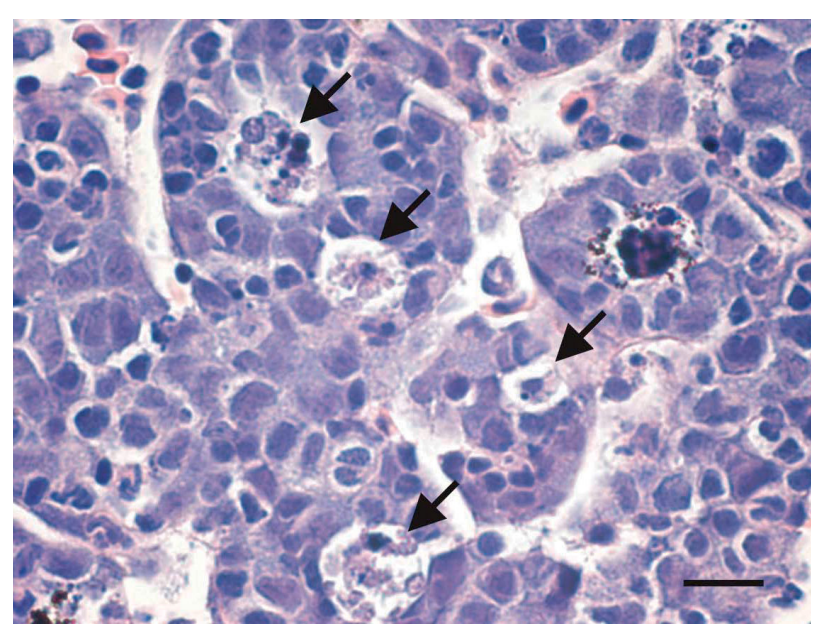

Fig. 4. Oncorhynchus mykiss. Area of haematopoietic cellular degeneration (arrows) within the head kidney, with adjacent normal architecture; scale bar $=20 \mu \mathrm{m}$

\section{Gross pathology of fish from serial live sampling}

The presence of gross lesions in the live-sampled rainbow trout followed a similar pattern as the mortality curves. For example, visceral adipose petechiation and ascites were found in samples collected between 14 and $35 \mathrm{dpi}$, peaking at 14 and $21 \mathrm{dpi}$, then present in decreasing frequency in the surviving fish. Additionally, gross cardiac changes were noted only at $35 \mathrm{dpi}$, consistent with the chronic, progressive nature of cardiac lesions demonstrated in the fatally infected rainbow trout. The more nonspecific lesion of fin base haemorrhage followed a different pattern, as it remained present at a relatively constant level throughout the weeks of sampling, but in later weeks was accompanied by mild fin erosion suspected to be related to either a mild fungal infection or due to mechanical irritation from the small diameter fiberglass coated tanks.

\section{Histopathology of fish from serial live sampling}

For microscopic examination, a rating scale (Moneke et al. 2005) for ISAV-related rainbow trout lesions was minimally revised based on the findings of the recent mortalities or moribund fish summarized in Table 6 . This rating scale was applied to the fish sampled weekly in an attempt to discern the development of the lesions. The histologic examination was performed on tissues from fish sacrificed at weekly intervals for the first 4 wk of the infection $(7,14,21$ and $28 \mathrm{dpi})$. These times were chosen because they flanked the time of death of the majority of fish. Additionally, only tissues of fish inoculated with virus propagated in the CHSE-
214 cell line were evaluated. These were chosen since the very high cumulative mortalities of Atlantic salmon in the highest virus dose of TO-propagated ISAV limited the number of survivors for sampling to the first 3 wk post challenge. Limiting detailed histologic evaluation to the fish infected with CHSE-214-propagated ISAV was further justified since the survival analysis of the 2 different virus preparations at $10^{4.13} \mathrm{TCID}_{50}$ did not indicate a significant cell line associated change in virulence for either species of fish (for rainbow trout $p=0.071$; for Atlantic salmon $p=0.205$ ) as reported above. All slides were randomized and read blind.

The histopathologic lesions observed in the livesampled fish are summarized in Table 8. A subsample of uninfected control tank fish from both species was included to assess pre-existing lesions. The lesions in Atlantic salmon were consistent with those previously reported for ISA, with the most prominent finding of focally extensive to bridging areas of acute haemorrhagic necrosis in the liver (Evensen et al. 1991). In the rainbow trout, no liver lesions were observed and there was no evidence of congestion in the renal interstitium or the lamina propria of the foregut. The main microscopic lesions in the rainbow trout were renal haematopoietic cellular degeneration, increased erythrophagocytosis as assessed within the interstitium and vasculature of the anterior kidney, and cardiac endothelial cell hypertrophy/cellularity. These lesions were seen with an apparent virus dose-dependent incidence in the challenged fish. Mild pericholangitis was seen within the livers of rainbow trout regardless of sampling date or viral dose used. As this lesion was consistently mild and ubiquitous, it is considered an incidental finding.

\section{ISH in rainbow trout tissues}

A riboprobe specific for mRNA transcripts of ISAV Segment 7 labeled with digoxigenin-11-UTP was constructed as previously described (Moneke et. al. 2003), and was used to demonstrate the cellular distribution of ISAV gene expression in putative ISAV lesions in experimentally infected rainbow trout from a subsequent experimental challenge trial. Fig. 6 shows virus detection by ISH in liver and heart tissues from fish from serial live sampling. The blue colour seen in a positive reaction was apparent only within the endothelium of the tissues, the primary target cell of ISAV.

\section{DISCUSSION}

Although it has been widely reported that experimental ISAV infection of salmonids other than Atlantic 

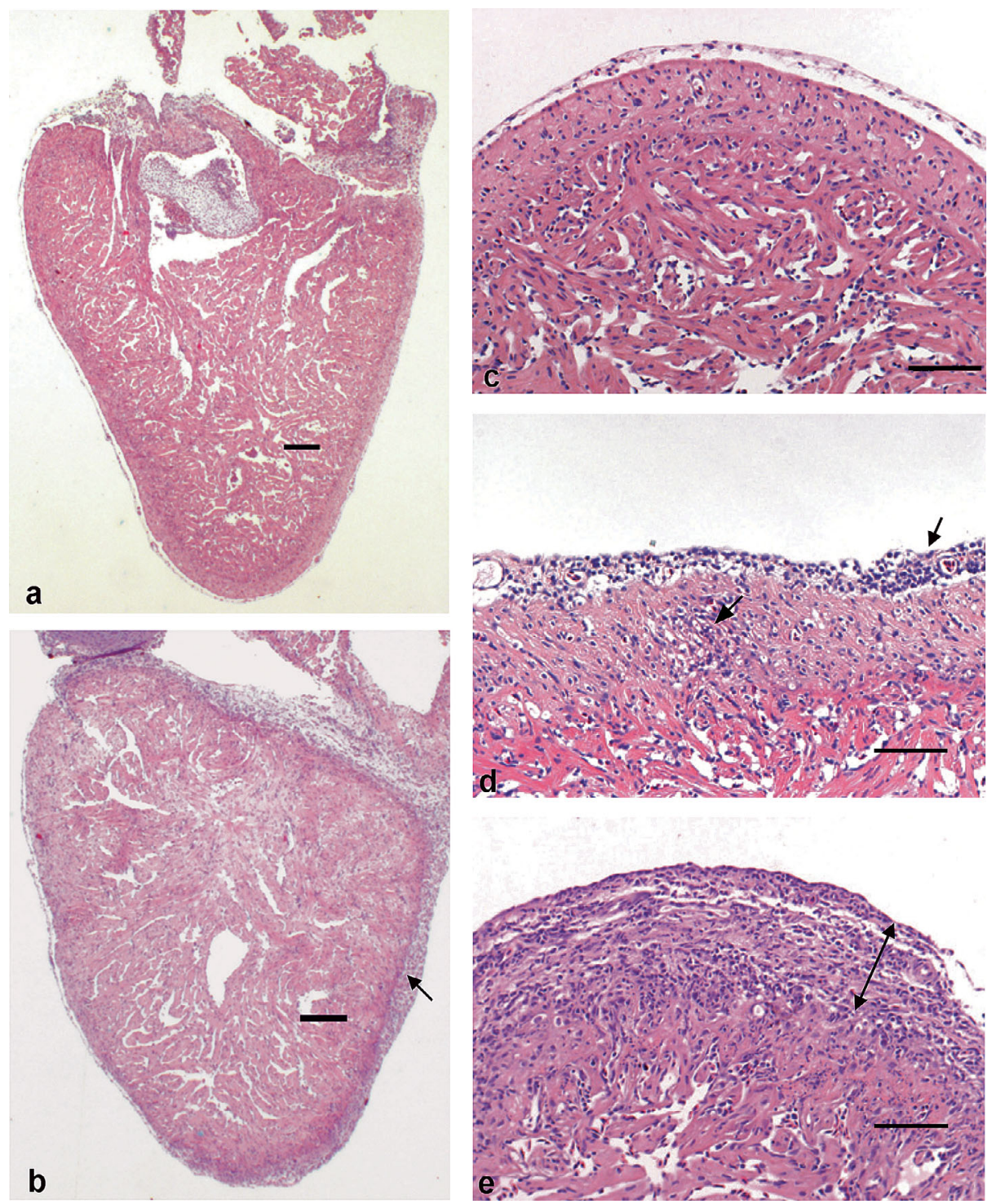

Fig. 5. Oncorhynchus mykiss. (a) Ventricle from normal fish; scale bar $=200 \mu \mathrm{m}$. (b) Ventricle from infectious salmon anaemia virus (ISAV)-infected fish showing inflammatory cell infiltrate of the epicardium and apparent loss of the adjacent compact layer (arrow); scale bar $=200 \mu \mathrm{m}$. (c) Ventricle from normal fish at higher magnification, showing pericardium, compact and spongy layers; scale bar $=100 \mu \mathrm{m}$. (d) Ventricle from ISAV-infected fish showing mild inflammatory cell infiltration of the epicardium (solid arrow) and area of myositis within the compact layer (open arrow); scale bar $=100 \mu \mathrm{m}$. (e) Ventricle from ISAV-infected fish showing epicarditis and endocarditis extending through the compact layer (double-headed arrow); scale bar $=100 \mu \mathrm{m}$

salmon results in asymptomatic infection (Nylund et al. 1994, 1995a, 1997, 2003, Nylund \& Jakobsen 1995, Rolland \& Nylund 1998, Snow et al. 2001, Rolland \& Winton 2003), those studies were based on single ISAV isolates that did not encompass the wide spectrum of ISAV virulence. In an attempt to identify and characterize the correlates of pathogenicity of ISAV, we previously studied the infectivity of different ISAV isolates in 3 farmed fishes, Atlantic salmon, coho salmon, and rainbow trout. It was shown that the ISAV isolates that are highly pathogenic for Atlantic salmon also cause mortality in rainbow trout (Kibenge 2004, Kibenge et al. 2004, 2006). The experimental reproduction of ISAV-induced mortality in rainbow trout with ISAV isolate NBISA01 in the present study conclusively demonstrates the virulence of ISAV for salmonids such as rainbow trout. In the present paper we describe further investigations of the pathology associated with experimental ISAV infection in rainbow trout. The limited nature of the gross and microscopic pathology lesions seen in the infected rainbow trout indicates that this species is highly resistant to developing ISA. As 
Table 8. Salmo salar and Oncorhynchus mykiss. Prevalence (Prev.) of histopathologic lesions in fish sampled at Days 7, 14, 21, and 28 after infection with ISAV

\begin{tabular}{|c|c|c|c|c|c|c|}
\hline \multirow[t]{2}{*}{ Histopathologic lesion } & \multicolumn{3}{|c|}{ Atlantic salmon } & \multicolumn{3}{|c|}{ Rainbow trout } \\
\hline & $\begin{array}{c}\text { Control } \\
(\mathrm{n}=8) \\
\text { Prev. }\end{array}$ & $\begin{array}{c}10^{2.13} \\
(\mathrm{n}=8) \\
\text { Prev. }\end{array}$ & $\begin{array}{c}10^{7.13} \\
(\mathrm{n}=7) \\
\text { Prev. }\end{array}$ & $\begin{array}{c}\text { Control } \\
(\mathrm{n}=20) \\
\text { Prev. }\end{array}$ & $\begin{array}{c}10^{2.13} \\
(\mathrm{n}=20) \\
\text { Prev. }\end{array}$ & $\begin{array}{c}10^{7.13} \\
(\mathrm{n}=20) \\
\text { Prev. }\end{array}$ \\
\hline Renal haematopoietic cell degeneration & 0 & 3 & 4 & 2 & 7 & 12 \\
\hline Increased erythrophagocytosis & 1 & 3 & 3 & 2 & 6 & 12 \\
\hline Cardiac endothelial cell hypertrophy & 2 & 3 & 3 & 3 & 6 & 10 \\
\hline Liver congestion and haemorrhage & 0 & 1 & 2 & 0 & 0 & 0 \\
\hline Liver necrosis & 0 & 2 & 1 & 0 & 0 & 0 \\
\hline Renal congestion and haemorrhage & 0 & 0 & 2 & 0 & 0 & 0 \\
\hline Pyloric caeca congestion and haemorrhage & 0 & 2 & 1 & 0 & 0 & 0 \\
\hline Pericholangitis & 0 & 0 & 0 & 10 & 10 & 7 \\
\hline
\end{tabular}

these lesions differ from the typical necrosis in liver and kidney that occur in Atlantic salmon with ISA, if these lesions were viewed in rainbow trout under field conditions, it is unlikely that ISA would be considered as a differential diagnosis.

Regarding the deaths of the rainbow trout, there were insufficient numbers in the low- and mid-virus dose tanks from either cell line to discern any pattern other than sporadic, intermittent mortalities over time. This differs from the Atlantic salmon experimental infection model, where fish either die acutely or survive. While it is our interpretation that rainbow trout that are dying later than expected are succumbing to chronic disease processes, it could be argued that
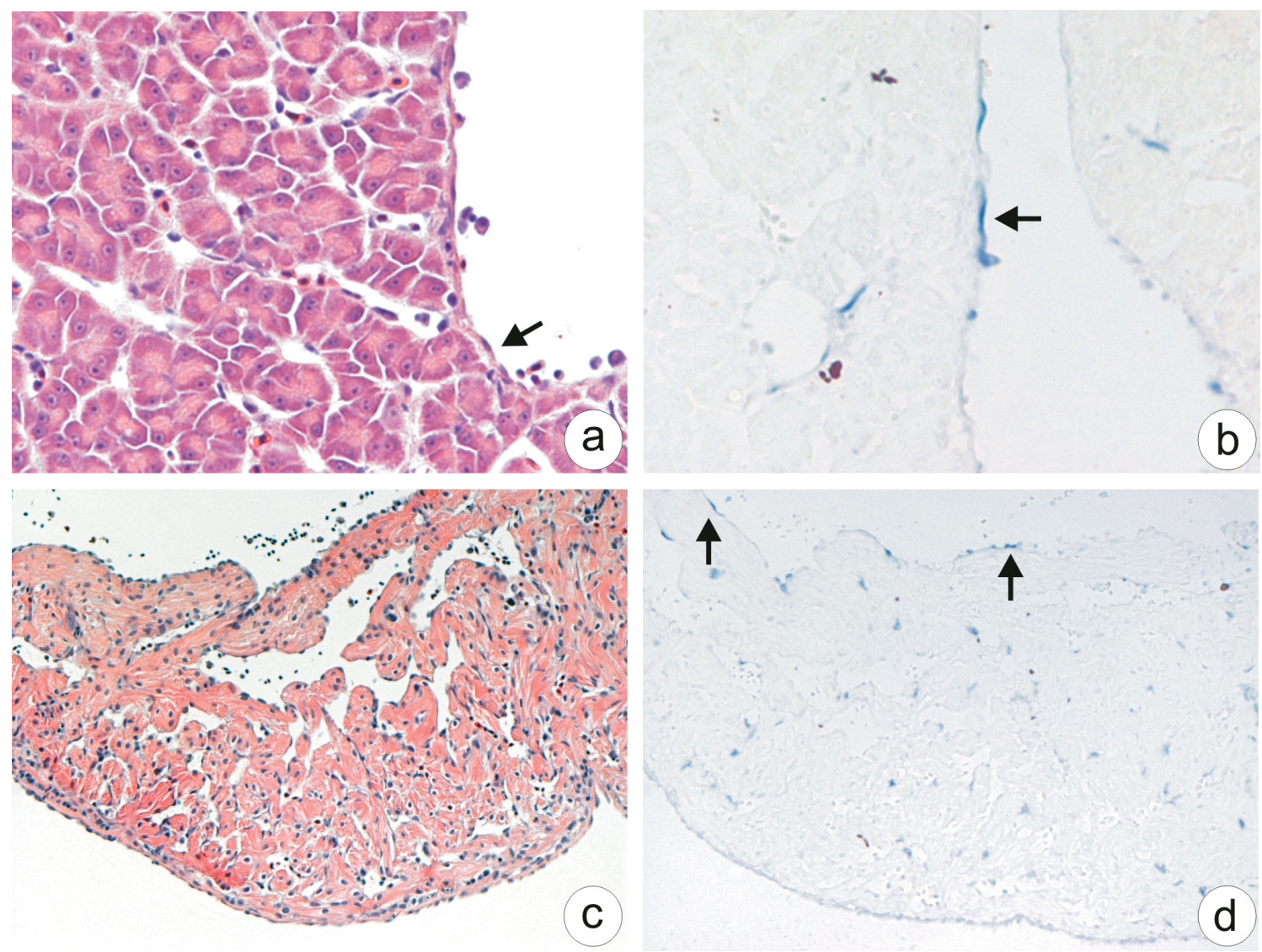

Fig. 6. Oncorhynchus mykiss. Serial histologic sections from rainbow trout liver (a,b; 160 magnification) and atrium (c,d; 100 magnification) $12 \mathrm{~d}$ post-infection with infectious salmon anaemia virus (ISAV). (a,c) H\&E staining, (b,d) in situ hybridization using antisense ISAV segment 7 riboprobe with no counter stain. Arrows indicate positive signal in endothelium 
cohabitation with highly susceptible Atlantic salmon, presumably shedding substantial quantities of virus into the environment, provided a reservoir for reinfection. Virus detection using RT-PCR yielded unexpected variable results. The sensitivity of this assay may have been lowered due to dilution by cellular RNA, as we extracted total RNA from samples consisting of pools of 3 organs. Virus detection in the weekly live sampling showed the highest number of positive samples at Day $14 \mathrm{pi}$, which coincided with the timing of the majority of acute mortalities when viral replication would be expected to be high. However, it is of interest to note that the 8 RT-PCR positive rainbow trout samples were not clustered in the early weeks of the trial, indicating possible viral replication as late as Day 49 pi in the high virus dose CHSE-214 tank.

A subset of Atlantic salmon was chosen to demonstrate that the lesions seen in this trial following intraperitoneal injection of ISAV were consistent with those lesions described in the literature (Thorud \& Djupvik 1988, Evensen et al. 1991, Speilberg et al. 1995, Totland et al. 1996). In other words, this species was included as a disease control to increase the validity of any findings in rainbow trout. The lesions seen in the Atlantic salmon subset were typical of ISAV lesions in previous experimental infections (Dannevig et al. 1994, Moneke et al. 2005). Similar gross lesions were seen in infected rainbow trout, but the distribution of the lesions was very different from those of Atlantic salmon. Fin base haemorrhage $(52 \%)$ was the most common finding, followed by visceral adipose petechiation $(44 \%)$, exophthalmia ( $44 \%)$, ascites $(41 \%)$, liver congestion $(22 \%)$, splenic congestion $(15 \%)$ and periorbital petechiation $(11 \%)$. Additionally, the haemorrhagic lesions in rainbow trout were less severe than those seen in Atlantic salmon and generally had a more limited distribution.

The histopathologic lesions in rainbow trout were very different from the typical necrosis in liver and kidney that occurred in Atlantic salmon; liver disease in rainbow trout was seen at a relatively low level as compared to Atlantic salmon. Sinusoidal congestion was seen in $40 \%$ and necrosis in only $8 \%$ of the rainbow trout mortalities examined. However, $41 \%$ of these fish had ascites. It has been hypothesized that portal hypertension secondary to peliosis-like hepatic lesions in Atlantic salmon plays a role in the development of ascites (Evensen et al. 1991, Speilberg et al. 1995). In the rainbow trout mortalities in the present study, there was a higher incidence of ascites than liver lesions. Cardiac dysfunction in Atlantic salmon, as demonstrated by a decreased Frank-Starling response, has been documented as part of the pathology of ISA, despite normal cardiac morphology (Gattuso et al. 2002). It was found that cardiac endothelial damage effects on nitric oxide homeostasis resulted in decreased cardiac output and stroke volume in response to increased filling pressures. This endothelium-related response to ISAV would also be expected in rainbow trout, but additional cardiac dysfunction and vascular flow compromise secondary to the cardiac lesions in this species may account for the development of ascites in the absence of significant liver disease. Nineteen percent $(5 / 27)$ of these rainbow trout had epicarditis of varying severity with adjacent myocarditis in the more severely affected fish. Surprisingly, this lesion was not seen in any of the livesampled fish (rainbow trout or Atlantic salmon), and it is not a lesion previously associated with ISA in Atlantic salmon. Differential diagnoses for epicarditis in salmonids include cardiomyopathy syndrome, heart and skeletal muscle inflammation and salmon pancreas disease. However, the signalment (rainbow trout parr) and lack of involvement of the exocrine pancreas, skeletal musculature and spongy layer of the ventricle are sufficient to conclude that the clinical signs demonstrated in this infection trial are inconsistent with these diseases (Rodger \& Turnbull 2000, Desvignes et al. 2002, Poppe \& Seierstad 2003, Kongtorp et al. 2004 ). It is our considered opinion that this unique lesion is characteristic of fatal ISAV-infection of rainbow trout.

Within the kidney, interstitial congestion of the haematopoietic tissue of the head kidney $(15 \%)$ and renal necrosis $(4 \%)$ were of low incidence in the infected rainbow trout mortalities. Renal haematopoietic cellular degeneration, which has previously been reported in ISAV outbreak of a commercial Atlantic salmon farm (Evensen et al. 1991), was a frequent finding in both species $(92 \%$ of rainbow trout and $67 \%$ of Atlantic salmon) although its clinical relevance is presently unknown. Increased erythrophagia was also common in both species $(80 \%$ of rainbow trout and $67 \%$ of Atlantic salmon). Based on counts of erythrophagocytosis per 5 high powered fields in the rainbow trout, the highest levels were seen in the fatally infected fish. But among the routine sampled fish, a pattern was evident in that there was an increase in severity of erythrophagocytosis, with higher levels seen in the survivors of the CHSE-214propagated ISAV high-dose tank as compared to the CHSE-214-propagated ISAV low-dose tank as compared over time (data not shown). The prominence of this lesion in infected rainbow trout that did not die or took a long time to die has led us to speculate that it may be indicative of an antiviral response by a resistant host to the ISAV infection. We are convinced that the lesions and mortalities seen in this study are due to ISAV infection. In a subsequent rainbow trout challenge trial, virus was detected in the endothelium of the rainbow trout tissues using ISH, supporting our 
contention that these lesions were caused by ISAV infection.

Haematocrit evaluations from the rainbow trout populations determined that the ISAV-infected tanks had mean haematocrit values that were significantly lower than those of the control rainbow trout. Among the infected rainbow trout groups, the reduced haematocrit values persisted throughout the duration of the experiment without rebounding to normal levels as has been previously reported (Nylund et al. 1997, Snow et al. 2001). While a significant difference was found between the reduced haematocrit values in infected rainbow trout as compared to the controls, it should be noted that none of the rainbow trout that died during this trial (between 6 and $36 \mathrm{dpi}$ ) demonstrated pale gills, supporting the absence of anaemia (Table 2).

The ISAV isolate NBISA01 used in this study was highly pathogenic for Atlantic salmon as previously reported (Kibenge 2004, 2006). In the present study, the virus produced a percent cumulative mortality of $88.09 \%$ (74/84) in the highest virus dose group of Atlantic salmon. Among the infected rainbow trout, the percent cumulative mortality in the highest virus dose group was $38.8 \%$ (31/80), slightly lower than what we previously observed (Kibenge et al. 2004, 2006), although the difference might simply be due to the larger number of fish used in the present study (i.e. 80 versus 10) or be related to the weekly sampling removing fish that might have died if left undisturbed. Survival analysis was used to compare the pathogenicity of different doses of ISAV, the effect of the cell line used to propagate the virus on the virulence of the virus, and the relative susceptibility of different fish species to ISA. The MTTF, the time at which there is a $50 \%$ probability of death of the study population, was significantly lower for both species in the higher virus dose than the lower virus dose tanks regardless of which cell line, TO or CHSE-214, the virus had been propagated in. Moreover, Atlantic salmon had a significantly shorter MTTF when compared to rainbow trout at all treatment levels for both sources of viral inoculum $(p=0.000)$.

Not all ISAV isolates are cytopathic in the CHSE-214 cell line (Kibenge et al. 2000). As this cell line is derived from Chinook salmon belonging to the same genus, Oncorhynchus, as rainbow trout, we hypothesized that the cell line used to propagate ISAV could influence its virulence, and further that the resistance of rainbow trout to ISAV infection reported in all previous experimental challenges might be overcome if the virus was grown in a closely related cell line. However, log-rank comparisons of the MTTFs for the virus propagated in TO or CHSE-214 cell line at the same virus dose $\left(10^{4.13} \mathrm{TCID}_{50} / 200 \mu \mathrm{l}\right.$ per fish) showed, no significant cell line-associated difference in either fish species. In fact, the MTTF for rainbow trout was lower in the TO grown virus than in the CHSE-214 grown virus, $\mathrm{MTTF}=30.09$ and 34.15, respectively $(\mathrm{p}=0.071)$. For Atlantic salmon, the difference was even less, 19.6 and 18.27, respectively ( $p=0.205$ ), probably because of their higher susceptibility to ISAV.

In conclusion, we report the first pathogenesis study detailing the pathology associated with experimental ISAV infection in rainbow trout. In contrast to the acute experimental disease experienced in Atlantic salmon, in rainbow trout there is evidence of both acute and protracted pathogenesis. As the lesions in rainbow trout are very different from the typical necrosis in liver and kidney that occur in infected Atlantic salmon with ISA, if these lesions were viewed in rainbow trout under field conditions, it is unlikely that ISA would have been considered as a differential diagnosis. Moreover, some of the lesions, like erythrophagia, may be indicative of an antiviral response by a resistant host to the ISAV infection. Virus was detected in the endothelium of the rainbow trout tissues using ISH, supporting our conclusions of the ISAV-induced lesions in this report.

Acknowledgements. This work was supported by an NSERC Strategic grant. The authors thank Patricia K. McKenna for technical assistance, and the staff of the AVC Aquatic Animal Facility for taking good care of the experimental fish.

\section{LITERATURE CITED}

Anonymous (2000) ISA hits the Faeroes. Fish Farming Int 27: 47

Bouchard DA, Brockway K, Giray C, Keleher W, Merill PL (2001) First report of infectious salmon anaemia (ISA) in the United States. Bull Eur Assoc Fish Pathol 21:86-88

Bryne PJ, MacPhee DD, Ostland VE, Johnson G, Ferguson HW (1998) Haemorrhagic kidney syndrome of Atlantic salmon, Salmo salar L. J Fish Dis 21:81-91

Dannevig BH, Falk K, Skjerve E (1994) Infectivity of internal tissues of Atlantic salmon, Salmo salar L., experimentally infected with the aetiological agent of infectious salmon anaemia (ISA). J Fish Dis 17:613-622

Desvignes L, Quentel C, Lamour F, Le Ven A (2002) Pathogenesis and immune response in Atlantic salmon (Salmo salar L.) parr experimentally infected with salmon pancreas disease virus (SPDV). Fish Shellfish Immunol 12: 77-95

Devold M, Krossøy B, Aspehaug V, Nylund A (2000) Use of RT-PCR for diagnosis of infectious salmon anaemia virus (ISAV) in carrier sea trout Salmo trutta after experimental infection. Dis Aquat Org 40:9-18

Dohoo I, Martin W, Stryhn H (2003) Modeling survival data. In: Veterinary epidemiologic research. AVC, Charlottetown, PEI, p 409-454

Evensen O, Thorud KE, Olsen YA (1991) A morphological study of the gross and light microscopic lesions of infectious anaemia in Atlantic salmon (Salmo salar). Res Vet Sci 51:215-222

Gattuso A, Mazza R, Imbrogno S, Sverdrup A, Tota B, Nylund A (2002) Cardiac performance in Salmo salar with infec- 
tious salmon anaemia (ISA): putative role of nitric oxide. Dis Aquat Org 52:11-20

Jones SRM, MacKinnon AM (1999) Virulence and pathogenicity of infectious salmon anemia virus isolated from farmed salmon in Atlantic Canada. J Aquat Anim Health 11:400-405

Kibenge FSB (2004) Molecular studies in infectious salmon anaemia virus (ISA). Bull Aquacul Assoc Can 104:71-78

Kibenge FS, Lyaku JR, Rainnie D, Hammell KL (2000) Growth of infectious salmon anaemia virus in CHSE-214 cells and evidence for phenotypic differences between virus strains. J Gen Virol 81:143-150

Kibenge FSB, Gárate ON, Johnson G, Arriagada R, Kibenge MJT, Wadowska D (2001) Isolation and identification of infectious salmon anaemia virus (ISAV) from Coho salmon in Chile. Dis Aquat Org 45:9-18

Kibenge FS, Munir K, Kibenge MJ, Joseph T, Moneke E (2004) Infectious salmon anemia virus: causative agent, pathogenesis and immunity. Anim Health Res Rev 5: 65-78

Kibenge FSB, Kibenge MJT, Groman D, McGeachy S (2006) In-vivo correlates of infectious salmon anaemia virus pathogenesis in fish. J Gen Virol 87:26452652

Kongtorp RT, Kjerstad A, Taksdal T, Guttvik A, Falk K (2004) Heart and skeletal muscle inflammation in Atlantic salmon, Salmo salar L.: a new infectious disease. J Fish Dis $27: 358$

Moneke E, Kibenge MJT, Groman D, Johnson GR, Ikede BO, Kibenge FSB (2003) Infectious salmon anaemia virus (ISAV) RNA in fish cell cultures and in tissue sections of Atlantic salmon experimentally infected with ISAV. J Vet Diagn Invest 15:407-417

Moneke E, Groman DB, Wright GM, Stryhn H, Johnson GR, Ikede BO, Kibenge FSB (2005) Correlation of virus replication in tissues with histologic lesions in Atlantic salmon experimentally infected with infectious salmon anemia virus. Vet Pathol 42:338-349

Mullins JE, Groman D, Wadowska D (1998) Infectious salmon anemia in salt water Atlantic salmon (Salmo salar L.) in New Brunswick, Canada. Bull Eur Assoc Fish Pathol 18: 100-114

Murray AG, Smith RJ, Stagg RM (2002) Shipping and the spread of infectious salmon anemia in Scottish aquaculture. Emerg Infect Dis 8:1-5

Nylund A, Jakobsen P (1995) Sea trout as a carrier of infectious salmon anaemia virus. J Fish Biol 47:174-176

Nylund A, Alexanderson S, Lovik P, Jakobsen P (1994) The response of brown trout (Salmo trutta L.) to repeated challenge with infectious salmon anaemia (ISA). Bull Eur Assoc Fish Pathol 14:167-170

Nylund A, Alexanderson S, Rolland JB, Jakobsen P (1995a) Infectious salmon anaemia virus (ISAV) in brown trout. J Aquat Anim Health 7:236-240

Nylund A, Kvenseth AM, Krossoy B (1995b) Susceptibility of wild salmon (Salmo salar L.) to infectious salmon anaemia (ISA). Bull Eur Assoc Fish Pathol 15:152-156

Nylund A, Kvenseth AM, Krossoy B, Hodneland K (1997) Replication of the infectious salmon anaemia virus (ISAV) in rainbow trout, Oncorhynchus mykiss (Walbaum). J Fish Dis 20:275-279

Nylund A, Devold M, Plarre H, Isdal E, Aarseth M (2003)

\section{Editorial responsibility: Managing Editor}

Emergence and maintenance of infectious salmon anaemia virus (ISAV) in Europe: a new hypothesis. Dis Aquat Org 56:11-24

O'Halloran JL, L'Aventure JP, Groman DB, Reid AM (1999) Infectious salmon anemia in Atlantic salmon. Can Vet J 40: 351-352

OIE (Office Internationale des Epizooties) Report (2007) Infectious salmon anaemia, Chile. Available online at: www.oie.int/wahid-prod/public.php?page=single_report\& pop=1\&reportid=5890 (accessed August 13, 2007)

Olfert ED, Cross BM, McWilliam A (1993) A guide to the care and use of experimental animals. Bradda Printing Services, Ottawa, ON

Poppe TT, Seierstad SL (2003) First description of cardiomyopathy syndrome (CMS)-related lesions in wild Atlantic salmon Salmo salar in Norway. Dis Aquat Org 56:87-88

Raynard RS, Murray AG, Gregory A (2001) Infectious salmon anaemia virus in wild fish from Scotland. Dis Aquat Org 46:93-100

Reed LJ, Muench H (1938) A simple method of estimating endpoints. Am J Hyg 27:493-497

Ritchie RJ, Cook M, Melville KJ, Simard N, Cusack R, Griffiths S (2001) Identification of infectious salmon anemia virus in Atlantic salmon from Nova Scotia (Canada): evidence for functional strain differences. Dis Aquat Org 44: 171-178

Rodger H, Turnbull T (2000) Cardiomyopathy syndrome in farmed Scottish salmon. Vet Rec 146:500-501

Rodger HD, Turnbull T, Muir F, Millar FS, Richards RH (1998) Infectious salmon anaemia (ISA) in the United Kingdom. Bull Eur Assoc Fish Pathol 18:115-120

Rolland JB, Nylund A (1998) Sea running brown trout: carrier and transmitter of the infectious salmon anemia virus (ISAV). Bull Eur Assoc Fish Pathol 18:50-55

Rolland JB, Winton JR (2003) Relative resistance of Pacific salmon to infectious salmon anaemia virus. J Fish Dis 26: $511-520$

Siggins L (2002) Salmon virus detected in Clew Bay fish farm. Irish Times. 12 August 2002; also available at: www.ireland.com

Simko E, Brown LL, MacKinnon AM, Byrne PJ, Ostland VE, Ferguson HW (2000) Experimental infection of Atlantic salmon, Salmo salar L., with infectious salmon anaemia virus: a histological study. J Fish Dis 23:27-32

Snow M, Raynard RS, Bruno DW (2001) Comparative susceptibility of Arctic char (Salvelinus alpinus), rainbow trout (Oncorhynchus mykiss) and brown trout (Salmo trutta) to the Scottish isolate of infectious salmon anaemia virus. Aquaculture 196:47-54

Speilberg L, Evensen O, Dannevig BH (1995) A sequential study of the light and electron microscopic liver lesions of infectious anemia in Atlantic salmon (Salmo salar L.). Vet Pathol 32:466-478

Thorud KE, Djupvik HO (1988) Infectious anaemia in Atlantic salmon (Salmo salar L.). Bull Eur Assoc Fish Pathol 1: 155-162

Totland GK, Hjeltnes BK, Flood PR (1996) Transmission of infectious salmon anaemia (ISA) through natural secretions and excretions from infected smolts of Atlantic salmon Salmo salar during their presymptomatic phase. Dis Aquat Org 26:25-31

Submitted: May 25, 2005; Accepted: August 21, 2007

Proofs received from author(s): October 24, 2007 